\title{
THE CONCEPT OF THE IDEAL LEADER IN NAJIB KAILANI'S NOVEL AN-NIDĀ'UL KHĀLID: MICHAEL RIFFATERRE'S SEMIOTIC ANALYSIS
}

\author{
Qurratul Aini ${ }^{1}$ \\ ${ }^{1}$ Universitas Islam Negeri Sunan Kalijaga Yogyakarta \\ 1ainienie6@gmail.com
}

\begin{abstract}
A leader is someone who is elected by the community for the common good. The concept of a leader includes not only those who hold positions in the government system, but also religious leaders.. This study aims to describe the ideal leader in Najib Kailani's An-Nidaul Khalid novel by using Michael Riffaterre's semiotics as an analytical tool. The method used in this research is descriptive qualitative analysis by describing the data in accordance with what it is then followed by analysis. The data collection technique is using listening and note-taking techniques. The results of this study state that the concept of an ideal leader must comply with three things, namely: 1) The leader must be wise making decisions, 2) the leader must defend the interests and unite the people, and 3) the leader must accommodate the aspirations of the people. While, the matrix in the text is the concept of an ideal leader who has a model of nurturing and embracing the community, and a variant in the form of a text related to ideal leadership. The potential hypogram found in the text is the same as the matrix, namely the concept of an ideal leader, while the actual hypogram, departs from the true story experienced by the author, where he grew and developed along with the outbreak of World War II, then in 1958-19865 went in and out of prison, and In 1982, the novel An-Nidaul Khalid was published.
\end{abstract}

Keywords: Ideal Leader Concept, Semiotic, Riffaterre, Novel, Najib Kailani.

$$
\begin{aligned}
& \text { ملخص } \\
& \text { القائد هو الشخص الذى ينتخبه المجتمع من أجل المصالح العامة، ولم يقتصر مفهوم القائد على أصحاب المناصب }
\end{aligned}
$$

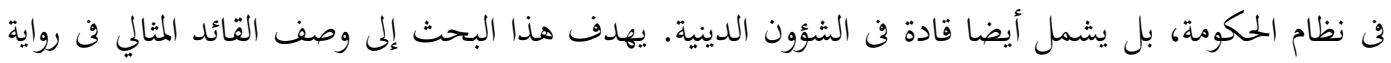

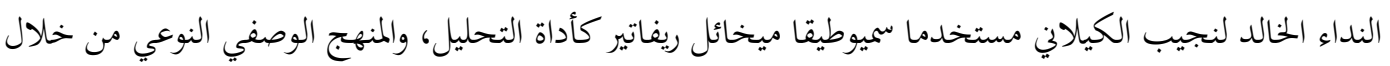

$$
\begin{aligned}
& \text { وصف البيانات وفقا لمتطلبات التحليل. في مرحلة جمع البيانات يستخدم طريقة الاستماع وتسجيل المعلومات. وقد }
\end{aligned}
$$

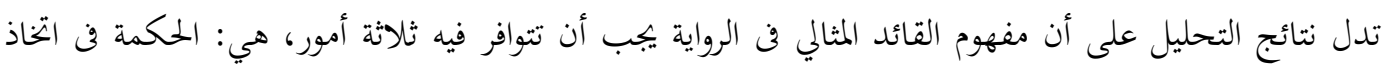

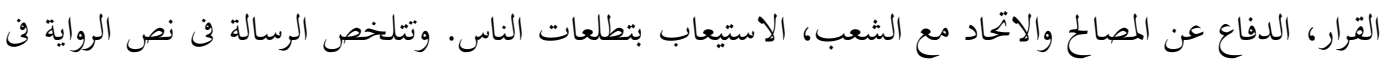

$$
\begin{aligned}
& \text { مفهوم القائد المثالي الذى له نموذج مثالي في رعاية واحتضان الناس وفن أنواع الخطابات النصية المتعلقة بمفهوم القائد }
\end{aligned}
$$

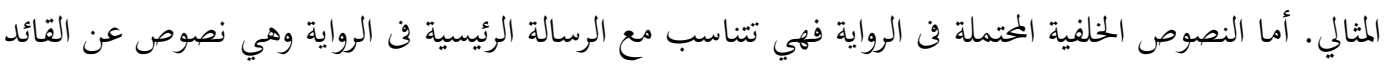

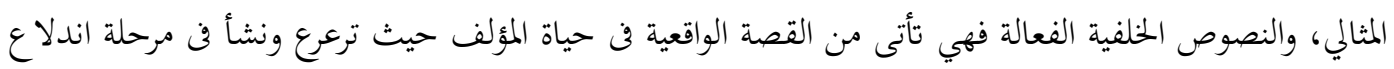

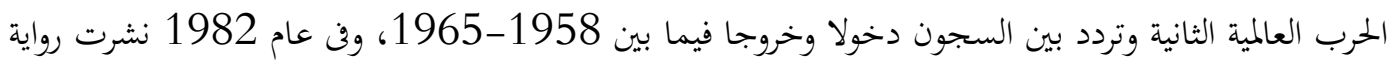

$$
\begin{aligned}
& \text { النداء الخالد. } \\
& \text { الكلمات المفتاحية: مفهوم القائد المثالي، سميوطيقا، ريفاتير، رواية، نجيب الكيلاني. }
\end{aligned}
$$




\section{A. Pendahuluan}

Karya Sastra merupakan suatu bentuk imajinasi berupa ide yang dituangkan oleh pengarang dalam bentuk tulisan (Imron, 2017:1). Ratna (2004:312) menyebutkan, imajinasi yang ada dalam karya sastra didasarkan pada kenyataan yang dialami oleh pengarang sebagai pencipta karya sastra. Sejalan dengan hal tersebut, Sumardjo dan Saini (1997:3-4) menyebutkan bahwa karya sastra merupakan ungkapan pribadi pengarang, baik itu berupa pengalaman, pemikiran, perasaan, ide dalam suatu bentuk gambaran nyata dengan memakai sarana bahasa sebagai alat penyampaian pesan. Sarana bahasa digunakan secara sistematis dengan sengaja dalam karya sastra, sehingga pengarang memiliki kebebasan untuk menuangkan aspirasi idenya dalam karya (Wellek, 1993:15).

Kebebasan pengarang dalam menuangkan proses kreatifnya dalam karya tidak hanya dipandang sebagai karya fiksi semata, namun ia juga dipandang sebagai dokumen sosial budaya (Siswanto, 2008:192). Sebagai sebuah dokumen, karya sastra dianggap sebagai bagian dari budaya. Hal ini didasarkan pada pendapat yang mengatakan bahwa karya sastra lahir di tengah masyarakat sebagai hasil imajinasi serta cerminan terhadap gejala sosial yang yang ada dalamnya (Pradopo, 2002:61). Mengacu pada pemikiran tersebut, Endraswara (2003:78) menyebutkan bahwa karya sastra merupakan ekspresi kehidupan manusia yang tidak bisa dilepaskan dari akar masyarakat. Sebagai sebuah fiksi, karya sastra memiliki beberapa genre yang sering dijadikan sebagai objek material dalam penelitian. Salah satu genre yang ada dalam karya sastra adalah novel.

Novel merupakan genre sastra yang berbentuk prosa serta memiliki unsur intrinsik dan ekstrinsik. Kata novel sendiri berasal dari bahasa Italia novella yang memiliki arti kisah atau cerita (Ahyar, 2019:148). Diantara beberapa genre fiksi dalam karya sastra, genre prosa khususnya novel memiliki unsur yang paling dominan dalam menampilkan unsur-unsur sosial
(Ratna, 2004:335). Hal ini karena novel dianggap sebagai karya yang menampilkan cerita paling lengkap, dan bahasa yang digunakan merupakan bahasa sehari-hari yang mudah dipahami oleh masyarakat luas. Hal ini dapat mengidentifikasi bahwa novel dapat digunakan sebagai media penyampai pesan yang paling efektif dalam masyarakat.

Novel An-Nidaül Khälid merupakan salah satu novel karya Najib Kailani seorang sastrawan kenamaan di Mesir. Najib Kailani merupkan sastrawan yang pernah beberapa kali merasakan suasana penjara, yaitu ketika ia bersama dengan kelompok Al-Ikhwan yang menentang rezim pemerintah. Masa pertumbuhannya bersamaan dengan pecahnya perang dunia II, dimana Mesir dijajah oleh Inggris pada saat itu (Al Kailani, 2000: III-IV). Hal inilah yang menjadi pemicu dan mempengaruhi berbagai karya Najib Kailani. Dengan demikian, maka Najib Kailani secara gamblang dapat mengambarkan kisah revolusi Mesir disertai dengan beberapa konflik yang dialami oleh tokoh.

Novel An-Nidaul Khälid mengisahkan kejahatan, pengkhianatan dan penindasan yang dialami oleh orang Mesir. Secara singkat novel ini berisi tentang perjuangan orang Mesir melawan kaum penjajah untuk memperoleh kemerdekaan dan kebebasan, sehingga kaum pribumi dapat hidup dengan damai di tanah tempat kelahirannya. Revolusi ini memakan waktu yang tidak sedikit, sehingga para tokoh pribumi dalam cerita harus melalui banyak konflik kekerasan dan kerja paksa.

Novel ini menjadi menarik untuk diteliti, karena menyajikan cerita yang sangat komplek tentang perjuangan Mesir melawan tirani penjajah, hingga pemerintah mengumandangkan kata kemerdekaan. Sebagaimana tergambar dalam novel, setiap proses revolusi tidak lepas dari adanya tindak kekerasan dalam prosesnya. Untuk melihat bagaimana simbol kekerasan yang digambarkan oleh Najib Kailani dalam novel An-Nidaul Khalid diperlukan sebuah teori bedah yang berkaitan dengan masalah yang akan 
dikaji. Berdasarkan hal tersebut, penulis menggunakan teori semiotika Michael Riffatere sebagai alat bedah.

Setelah peneliti melakukan pencarian yang mendalam tentang penelitian yang berkaitan dengan novel An-Nidaul Khalid karya Najib Kailani, dengan menggunakan teori Michael Riffatere sebagai pisau bedah yang berfokus pada konsep pemimpin ideal, penelitian tentang hal tersebut belum ada sebelumnya. Namun peneliti menemukan beberapa penelitian yang menggunakan novel An-Nidaul Khalid sebagai objek formal dalam penelitian, tapi menggunakan teori yang berbeda. Beberapa penelitian tersebut diantaranya adalah: 1) Tesis Azzuhri (2008) yang menyimpulkan bahwa nasionalisme religius bersumber dari ajaran islam, sedangkan pesan-pesan nasionalisme religius dalam dua novel Al-YaumulMau'ud dan An-Nidā'ul Khālid Karya Najib Kilani disampaikan melalui para tokoh. 2) Tesis Latifi (2004) yang membahas tentang post-nasional dalam novel An-Nidā'ul Khālid, dimana gagasan tersebut ditawarkan oleh novel dengan bercirikan pada identitas budaya yang bersifat hibrid dan diasporik. 3) Skripsi Utami (2018) yang membahas rekam sejarah, fakta sosial, dan dunia kepengaran yang ada dalam novel An-Nidaul Khalid.

Melihat beberapa kajian pustaka yang telah disebutkan tersebut, maka dapat dikatakan bahwa penelitian ini memilki kebaharuan yang berkaitan dengan teori yang digunakan serta fokus penelitian yang mengkaji tentang simbol kekerasan. Penelitian ini berusaha menjawab pertanyaan tentang bagaimana konsep pemimpin ideal yang ada dalam novel $A n$ Nidaul Khalid karya Najib Kailani dengan menggunakan teori semiotika Michael Riffatere.

\section{B. Metode Penelitian dan Kerangka Teori}

Metode penelitian yang digunakan dalam penelitian ini adalah metode deskriptif analisis yang mendeskripsikan fakta-fakta temuan dalam bentuk analisis (Hikmat, 2011:83). Adapun teori yang digunakan adalah teori semiotika Riffatere. Penelitian ini masuk dalam kategori penelitian kepustakaan yang mengkaji tentang ilmu-ilmu lain yang terkait dengan penelitian.

Data yang digunakan dalam penelitian ini terdiri dari dua bagian, yaitu data primer dan data sekunder. Data primer merupakan novel An-Nidaul Khälid karya Najib Kailani, sedangkan data sekunder berupa jurnal, tesis, skripsi, ataupun buku teks yang berkaitan yang objek kajian. Adapun teknik pengumpulan data menggunakan teknik simak dan catat, yaitu dengan cara melakukan pencarian, pembacaan dan kemudian dilanjutkan dengan mencatat data-data yang telah ditemukan baik dari data primer maupun sekunder yang berkaitan dengan tema yang akan diteliti. Setelah data terkumpul, kemudian dilanjutkan ke tahap analisis data.

Semiotika merupakan ilmu yang membahas tentang tanda-tanda, fenomena sosial budaya, termasuk didalamnya sastra yang dianggap sebagai sistem tanda. Tanda memiliki dua aspek penting, yaitu penanda dan petanda. Penanda merupakan bentuk formal dari tanda itu sendiri, sedangkan petanda merupakan arti dari apa yang ditandai oleh penanda (Pradopo, 1999: 76). Sehingga untuk menentukan makna dalam kajian semiotika harus terlebih dahulu mencari penanda dan petandanya. Ada beberapa tokoh sastra yang menggunakan konsep semiotik dalam teorinya, salah satunya adalah Michael Riffatere.

Dalam bukunya "Semiotics of Poetry" Riffatere mengatakan bahwa ada empat hal penting yang harus diperhatikan dalam memaknai karya sastra, yaitu; 1) karya sastra merupakan ekpsresi tidak langsung, yang menyatakan suatu hal dengan hal yang lain. 2) pembacaan heuristik dan pembacaan hermeneutik. 3) matriks, model, dan varian. 4) hipogram (Pradopo, 1999:77). Dengan memerhatikan empat hal tersebut, maka akan ditemukan makna keseluruhan dari sebuah karya. Adapun penjelasannya adalah sebagai berikut:

a. Ekspresi Tidak Langsung Ekpresi tidak langsung dalam karya 
sastra dapat diakibatkan oleh beberapa hal, yaitu penggantian arti, penyimpangan arti, dan penciptaan arti (Pradopo, 1999:77). Megacu pada hal tersebut, maka pembaca harus mampu mengatasi jika berhadapan dengan teks yang tidak gramatikal, yang berbeda dengan ide-ide yang biasa dalam kenyataan.

b. Pembacaan Heuristik dan Hermenutik.

Pembacaan dalam karya sastra dibagi menjadi dua yaitu, pembacaan heuristik dan pembacaan hermeneutik (Nurgiyantoro, 2009:33). Pembacaan heuristik dianggap sebagai pembacaan tingkat pertama dalam semiotik yang membaca teks dalam karya sastra berdasarkan tata bahasa normatif, sedangkan pembacaan hermeneutik dianggap sebagai pembacaan semiotik tingkat kedua yang mengacu pada konvensi sastra (Pradopo, 1999:77). Pembacaan secara heuristik dikatakan belum dapat memberikan makna dalam karya sastra, namun pada fase kedua makna dapat diperoleh, yang dihasilkan dari tafsiran-tafsiran.

c. Matriks, Models, dan Varian

Teks merupakan bagian dari karya sastra, sedang teks itu sendiri berawal dari matriks, yaitu kata kunci atau intisari dari teks itu sendiri. Matriks sebenarnya tidak muncul di dalam teks, namun diaktualisasikan dalam bentuk model. Kemudian model dapat menentukan varian dalam teks (Syafethi, 2016:24-25). Matriks juga bisa dikatakan mengarah pada sebuah tema dalam teks melalui pencarian model dan varian kemudian abstraksi matriks ditemukan (Pradopo, 1999: 77-78).

\section{d. Hipogram}

Hipogram merupakan bagian terpenting dalam teks. Dengan hubungan intertekstual ia dapat memberikan makna penuh dalam karya sastra. Hipogram dikatakan sebagai latar belakang sebuah karya sastra (Pradopo, 1999: 78). Hipogram dapat dibedakan menjadi dua yaitu; hipogram potensial dan hipogram aktual. Hipogram potensial dapat dicari dalam bahasa atau bentuk implikasi dari suatu makna kebahasaan, baik itu berupa makna konotasi ataupun berupa presuposisi yang ada dalam karya sastra, sedangkan hipogram aktual dapat dicari pada teks-teks sebelumnya yang ada di luar karya sastra, baik hal itu berupa mitos atau dalam bentuk karya sastra lain

Fokus penelitian ini adalah tentang konsep pemimpin ideal. Kata pemimpin merujuk pada suatu hal yang memengaruhi seseorang atau sekolompok orang untuk mencapai tujuan yang dicita-citakan besrsama (Hakim, 2007:37). Sama dengan pendapat Al-Ghazali yang mengatakan bahwa hakikat pemimimpin adalah kata pengaruh. Sehingga orang yang dimaksud dengan pemimpin adalah orang yang berpengaruh atau orang memiliki pengaruh dalam masyarakat (Al-Ghazali, t.t:295).

Konsep pemimpin ideal menurut Al-Ghazali (t.t:8) harus terdiri dari tiga hal, yaitu ilmu/intelektualitas, agama, dan akhlak. Akal dapat digunakan untuk membedakan manusia dengan ciptaan lainnya. Akal memunculkan ilmu pengetahuan sebagai proses dari berfikir yang dituntun oleh jiwa keagamaan. Dengan agama manusia memiliki ilmu dan begitu pula sebaliknya, agama yang berisi peraturan dapat dijalani dengan adanya ilmu. Tanpa adanya agama, manusia akan sesat dan matinya hati. Tanpa adanya ilmu, jiwa akan sekarat.

Akal atau intelektualitas yang digagas oleh Al-Ghazali berkaitan dengan konsep pemimpin ideal yang merupakan suatu perwujudan dari naluri alamiah, dan untuk melihat hal tersebut perwujudan dari akal harus dimunculkan, yaitu ilmu pengetahuan. Ada empat tingkatan akal menurut Al-Ghazali, yaitu akal berarti kecerdasan, pengertian, pengetahuan, ma'rifah (Ahmad, 1975:68).

Agama merupakan hal yang paling dasar yang ada dalam diri manusia, yang di dalamnya terdapat kata iman. Dengan iman inilah pemikiran tentang konsep pemimipin ideal masuk, dan dengan iman 
pemimpin dapat memimpin umatnya berdasarkan dasar keimanan. Semakin tinggi tingkat keimanannya pemimpin ideal akan dapat mewarisi daya keimanan yang dimiliki Rasulullah (Afriansyah, 2017:88).

Adapun akhlak adalah sesuatu yang berkaitan dengan moralitas manusia. AlGhazali mengatakan bahwa kekuatan moral dapat bekerja untuk menjauhkan dan mengendalikan diri dari sifat destruktif. AlGhazali juga mengatakan bahwa ahklak yang mulia merupakan satu diantara sifat seorang pemimpin (Al-Ghazali, t.t: 47).

\section{Pembahasan}

Secara garis besar, gambaran tentang pemimpin ideal adalah pemimpin yang bisa memimpin bangsa atau masyarakat dalam semua jenis keadaan. Artinya pemimpin harus bersikap layaknya pemimpin, tidak mengkhianati masyarakat yang sedang dipimpin. Dengan pemimpin seperti ini, maka masyarakat akan mempercayakan segala urusan kehidupannya di tangan pemimpin.

Pandangan Najib Kailani tentang pemimpin ideal yang mampu menjadi penopang segala urusan masyarakat juga tergambarkan dalam novel An-Nidaul

\section{Khalid.}

\section{Pembacaan}

\section{Heuristik}

dan Hermeneutik

a. Bijakasana Dalam Mengambil Keputusan

$$
\begin{aligned}
& \text { فابتسم "الشيخ عنبة" في مرارة وقال : } \\
& \text { - عند ذاك تعم المذابح أنحاء القطر، ويغرقون }
\end{aligned}
$$

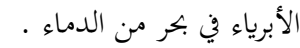

$$
\begin{aligned}
& \text { - ليكن . . إذ لا بد من التضحيات . ل }
\end{aligned}
$$

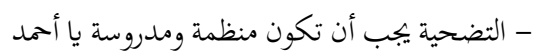

أفندي . . Kailani, 1981: 19)

Pembacaan heuristik pada potongan teks tersebut adalah sebagai berikut:

Kiai Anbah Tersenyum lebar dan berkata: "Kalau perang itu terjadi, pasti korban berjatuhan kemana-mana. Mesir akan banjir darah," komentarnya.
"Tentu, Kiai. Perjuangan mesti dengan pengorbanan."

"Hmm...., Nak Ahmad Affandy, tidak seenaknya, harus teratur dan memakai perhitungan"

Pembacaan hermeneutik adalah pembacaan pada tataran semiotik tingkat kedua, yaitu menggunakan pembacaan pada konvensi sastra, kemudian dilanjutkan dengan penafsiran-penafisran. Adapun pembacaan hermeneutik pada teks tersebut adalah sebagai berikut:

Pada teks percakapan antara Ahmad Affandy dan Kiai Anbah tersebut, terlihat bagaimana Kiai Anbah memakai perhitungan dalam segala tindakannya. Pada teks kalau perang itu terjadi, pasti korban berjatuhan kemana-kemana. Mesir akan bajir darah, kalimat ini menandakan bagaimana seorang yang dipercayai oleh masyarakat memikirkan segala kondisi dan akibat yang akan ditimbulkan dari suatu tindakan. Mesir akan banjir darah, mengidentifikasikan akan banyak masyarakat yang terluka dan terbunuh, tidak terkecuali masyarakat yang lemah.

Pada teks berikutnya terdapat tidak seenaknya, harus teratur dan memakai perhitungan. Teks ini mengidentifikasikan sebuah strategi yang harus digunakan, sehingga upaya melawan penjajah tidak hanya memiliki makna yang sia-sia dan strategi revolusi harus digunakan dalam upaya menumpas tirani penjajah.

$$
\begin{aligned}
& \text { - العنف في مثل هذه الحالة يعقد الأمور أكثر ، وما كان } \\
& \text { القتل تحت هذه الظروف وسيلة ناجحة . . الخوابة لن } \\
& \text { يقتله خنجر ، وإنما نستطيع أن نقضي عليه بوعينا ، }
\end{aligned}
$$

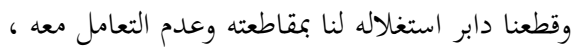

Pembacaan heuristik dalam kutipan novel diatas adalah sebagai berikut: "Kekerasan dan kebrutalan dalam situasi gawat begini akan menimbulkan banyak korban. Permasalahannya 
semakin rumit kalau kalian main hakim sendiri. Pembunuhan tidak mampu menyelesaikan persoalan dengan tuntas, karena pembunuh akan berhadapan dengan hukum. Namun kita dapat menghukum Yany. Kita dapat membunuhnya, tidak dengan pisau. Kesewenang-wenangan itu yang harus kita tumbangkan. Selama ia masih tamak, loba dan rakus, kita putuskan hubungan dengan dia.'

Adapun pembacaan hermeneutik dalam kutipan teks diatas adalah sebagai berikut:

Pada kutipan teks diatas terdapat teks yang berbunyi pembunuhan tidak maтри menyelesaikan persoalan dengan tuntas, karena pembunuh akan berhadapan dengan hukum. Teks ini mengisyaratkan kepada masyarakat bahwa pembunuhan bukan jalan pintas untuk menyelesaikan masalah yang sedang dihadapi. Penyelesaian dari permasalahan yang sedang dihadapi berada pada kutipan teks selanjutnya yaitu, selama masih tamak, loba dan rakus kita putuskan hubungan dengan dia. Yang artinya putuskan hubungan disini dalam segala aspek, sehingga jika orang yang belaku sewenang-wenang tidak berubah maka jangan pedulikan orang tersebut. Seperti pepatah yang mengatakan bahwa adanya seperti tidak ada, sehingga orang tersebut bisa anggap sebagai manusia yang transparan dalam masyarakat.

b. Membela Kepentingan dan Menyatukan Rakyat

ـ لكن الحرص لم يزل حيا . . كان "خفاجة" يدا تحركها

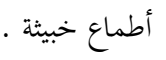

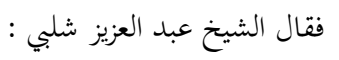
- ماذا تقصد ؟ - سائل نفسك . . لماذا حاول "خفاجة" أن يقتل العمدة؟ وهز "عبد العزيز" رأسة وسكت.

(Kailani, 1981: 148)

Pembacaan heuristik pada kutipan teks novel diatas adalah sebagai berikut: "Saudara-saudara mesti mengerti bahwa orang yang berada di belakang Khofajah masih hidup. Khafajah hanya sebagai tangan kanan dari orang yang memeras kalian"

Abdul Aziz Asy-Syalabi berkata: "Apa maksud pak Kiai?"

"Mestinya pak Syalabiy mengerti apa yang saya maksud, kenapa Khofajah berusaha untuk membunuh Lurah desa?"

Abdul Aziz terdiam sambil menganggukkan kepalanya.

Adapun pembacaan hermeneutik berdasarkan pada kutipan novel tersebut adalah sebagai berikut:

Dalam kutipan teks tersebut, terdapat teks yang berbunyi saudarasaudara mesti mengerti bahwa orang yang berada dibelakang Khafajah masih hidup. Teks ini mengindikasikan bahwa meskipun Khafajah terbunuh karena ulahnya sendiri, tapi jangan lupa orang yang berada dibalik ulah Khafajah tersebut. Kiai Anbah memberi peringatan kepada masyarakat bahwa kematian Khafajah bukanlah akhir, namun orang yang di belakang yang diartikan dengan orang yang memberi perintah masih hidup dan masih berkeliaran di desa tersebut. Kemudian pada kalimat selanjutnya ada kutipan teks yang berbunyi Khafajah hanya sebagai tangan kanan dari orang yang memeras kalian. Tangan kanan dalam teks tersebut diartikan sebagai orang kepercayaan yang menjadi andalan. Sehingga kematian Khafajah tidak berarti apaapa, masyarakat harus tetap hati-hati dan wapada. Kutipan ini memperlihatkan bagaimana seorang pemimpin memperhatikan masyarakatnya dalam segala situasi.

c. Menjadi Tumpuan Aspirasi Rakyat

$$
\begin{aligned}
& \text { - منا عبيد الحاجة ـ ـ لقد قهرنا الفقر . }
\end{aligned}
$$

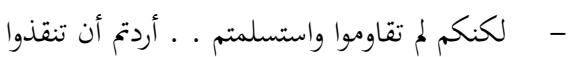

$$
\begin{aligned}
& \text { شيئا ففقدتم كل شيئ . }
\end{aligned}
$$

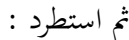




$$
\text { - ومع هذا فإني ألتمس لكم بعض المعاذير ، في هذا }
$$

( Kailani, 1981: 71)

Pembacaan Heuristik pada kutipan teks di atas adalah sebagai berikut:

"Kami membutuhkan banyak bahan makanan Kiai . . dan kami terlalu miskin"

"Kalian semestinya memberontak. Jangan menerima keadaan begitu saja. Mau menyelamatkan sesuatu yang kecil, semua kekayaan kalian hilang...." "Oleh karena itu, berilah kami jalan keluar yang bagus Kiai"

"Kita telah dikuasai oleh orang-orang kejam, rendah budi, serta tak punya hati nurani. Namun ingat.... Tuhanlah yang Maha Besar dan Kuasa....."

Adapun pembacaan hermeneutik pada kutipan teks novel diatas adalah sebagai berikut:

Dalam kutipan teks diatas terdapat teks yang berbunyi kalian semestinya memberontak, jangan menerima keadaan begitu saja. Kata memberontak pada teks tersebut bukan diartikan memberontak sebagaimana mestinya, namun memberontak disini menolak dan memeriksa keakuratan surat yang mereka tanda tangani sebagai bukti perjanjian. Kemudian pada teks berikutnya terdapat teks yang berbunyi namun ingat ... Tuhanlah yang Maha Besar dan Kuasa, yang menunjukkan bahwa penguasa yang zalim bukanlah seseorang yang memiliki kekuasaan penuh, masih ada Allah yang Maha atas segalanya. Kiai Anbah menampung segala bentuk aspirasi dan memberikan solusi yang baik. Ia juga memberikan peringatan, agar masyarakat terbebas dari tirani kezaliman orang yang berkuasa. Disamping peringatan yang diberikan oleh Kiai Anbah, ia juga mengingatkan bahwa ada Tuhan tempat mengadu yang punya kuasa lebih besar dibadingkan dengan para penguasa yang zalim.

$$
\begin{aligned}
& \text { - أجل . . أي حل لا يؤثر على كرامتي . . أو يجرح كبرياء }
\end{aligned}
$$

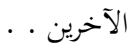

$$
\begin{aligned}
& \text { فهز "عنبة" رأسه قائلا : } \\
& \text {-لا بد من التضحية . . . ومستحيل أن يأتي الحل بدون } \\
& \text { ذالك. } \\
& \text { - أستطيع أن أضحي بنفسي . . أما كرامتى فلا . }
\end{aligned}
$$

( Kailani, 1981: 202)

Pembacaan secara heuristik pada kutipan teks novel diatas adalah sebagai berikut:

"Benar Kiai Anbah, tapi cara apa lagi yang hendak aku tempuh sedemikian tidak menggoyang serta menodai kehormatan dan kedudukanku di desa ini? apa kata orang-orang desa nantinya...."

Kiai Anbah manggut-manggut mendengar perkataan tersebut, ia menyadari dan mengerti maksud pak lurah, kemudian dia berkata;

"Harus ada pengorbanan pak Lurah, semua problematika di dunia ini tidak terpecahkan tanpa pengorbanan..."

"Benar Kiai. Dalam masalah ini aku dapat berkorban apa saja, namun kehormatanku?"

Adapun pembacaan hermeneutik yang mengacu pada kutipan teks diatas adalah sebagai berikut:

Dalam kutipan teks diatas terdapat teks yang berbunyi harus ada pengorbanan pak Lurah. Pengorbanan disini dimaksudkan bukan pengorbanan dalam arti yang sebenarnya, namun pengorbanan yang bersifat perasaan. Pengorbanan disini memiliki arti harus merendahkan ego untuk kebaikan bersama dan demi kebahagiaan anaknya. Kiai Anbah memberikan nasehat kepada pak Lurah, bahwa ia harus mengurangi egonya untuk memenuhi kepentingan yang lebih utama, sehingga kebahagiaan akan didapatkan oleh semua orang.

\section{Matriks, Model, dan Varian}

Matriks merupakan intisari dalam sebuah teks itu sendiri yang kehadirannya tidak ada dalam teks. Matrik yang terdapat dalam novel An-Nidaul Khalid karya Najib 
Kailani adalah "Konsep Pemimpin Ideal". Setelah ditemukan matriks dalam teks, kemudian dicari model yang ada dalam teks novel. Model yang ditemukan adalah "Mengayomi dan Merangkul Masyarakat". Berangkat dari model yang sudah ditemukan, kemudian dicari varian-varian yang ada dalam teks novel. Varian-varian tersebut adalah sebagai berikut.

a. Mesir akan banjir darah yang menandakan bahwa dalam mengambil tindakan harus selalu memikirkan segala konsekuensinya dalam masyarakat. Kemudian harus teratur dan memakai perhitungan yang artinya harus ada strategi dalam segala tindakan. Sehingga hal ini menandakan bahwa pemimpin bijaksana dalam mengambil keputusan.

b. Pembunuhan tidak menyelesaikan masalah dengan tuntas yang artinya bahwa ia memberi peringatan kepada masyarakat. Pembunuhan bukanlah cara untuk menyelesaikan masalah. Kemudian kita putuskan hubungan dengan dia yang artinya menyelasaikan masalah adalah dengan menganggap hadirnya orang yang membuat masalah tidak ada. Salah satu bentuk pemimpin ideal adalah bijaksana dalam bertindak dan memberi peringatan.

c. Memberontak yang artinya adalah memeriksa dan melihat isi surat dalam perjanjian. Kemudian Tuhan yang Maha Besar dan Kuasa yang artinya bahwa di atas segalanya masih ada Tuhan yang Maha Besar dan Kuasa atas segalanya. Pemimpin harus mendengarkan aspirasi rakyat dan memberi peringatan jika mereka melakukan kesalahan.

d. Pengorbanan yang memiliki arti menurunkan ego. Ketika masyarakat membutuhkan petuah untuk tingkah laku yang akan mereka lakukan, selaykanya pemimpin yang baik memberikan nasehat.

e. Di belakang Khofajah yang berarti bahwa ada orang yang memerintah tingkah laku Khofajah. Kemudian kata tangan kanan yang memiliki arti orang kepercayaan. Nasehat dan peringatan selalu dilontarkan oleh seorang pemimpin, yang artinya bahwa kematian Khofajah bukanlah akhir dari segalanya, masih ada orang yang lebih berkuasa di balik Khafajah.

\section{Hipogram}

Novel An-Nidaul Khälid karya Najib Kailani mencakup dua hipogram yang ada dalam karya sastra. Pertama, hipogram potensial yang sama dengan matriksnya "Konsep Pemimpin Ideal" dalam memimpin revolusi Mesir. Kedua, hipogram aktualnya adalah pecahnya perang dunia II ketika Najib Kailani berumur 8 tahun ketika penjajah Inggris mengeruk semua kekayaan para petani kapas. Kemudian pada tahun 1958-1965 ia pernah keluar masuk penjara, karena masuk dalam kelompok Al-Ikhwan yang merupakan oposisi pemerintah. Kemudian terbit novel An-Nidaul Khalid pada tahun 1981.

Konsep pemimpin yang ada dalam novel An-Nidaul Khalid hampir sama dengan konsep yang ditawarkan oleh AlGhazali tentang seorang pemimpin ideal. Seorang pemimpin yang berada dalam novel digambarkan oleh tokoh yang memiliki nama Kiai Anbah. Beliau merupakan seorang yang ahli strategi dan tidak gegabah dalam mengambil keputusan. Hal ini menunjukkan bahwa Kiai Anbah merupakan orang yang memiliki wawasan ilmu pengetahuan, seperti yang terdapat dalam kutipan:

$$
\text { - التضحية يجب أن تكون منظمة ومدروسة يا أممد أفندي }
$$

( Kailani, 1981: 19). . .

"Hmm...., Nak... Ahmad Affandy, tidak seenaknya, harus teratur dan memakai perhitungan"

Selain memiliki pengetahuan yang luas, Kiai Anbah juga digambarkan sebagai seseorang yang memiliki pemahaman agama yang sangat dalam. Dalam setiap geraknya dalam memimpin masyarakat selalu menyertakan Allah dalam segala urusannya. Dengan sifat yang demikian terlihat dengan jelas bahwa Kiai Anbah juga merupakan seseorang yang 
memiliki akhlak yang mulia seperti yang terdapat dalam kutipan :

$$
\text { - }
$$

(Kailani, 1981: 71)

"Kita telah dikuasai oleh orang-orang kejam, rendah budi, serta tak punya hati nurani. Namun ingat..... Tuhanlah yang Maha Besar dan Kuasa....."

Kiai Anbah termasuk dalam kriteria yang digambarkan oleh Al-Ghazali dalam konsep pemimpin ideal. Dalam novel, Kiai Anbah digambarkan dengan begitu ciamik, karismatik, penuh wawasan, dan menjadikannya sebagai tumpuan dari segala kebutuhan dan kepentingan masyarakat.

\section{Kesimpulan}

Berdasarkan pembahasan di atas dapat disimpulkan bahwa dalam novel $A n$ Nidaul Khalid karya Najib Kailani terdapat tiga hal yang masuk dalam kategori pemimpin ideal yang mengacu pada pembacaan heuristik dan hermeneutik teks sastra. Ketiga hal tersebut adalah: 1) Pemimpin harus bijaksana dalam mengambil keputusan, yang didasari pada asas kemaslahatan bersama dalam bermasyarakat. 2) Pemimpin harus membela kepentingan dan menyatukan rakyat, yang mengacu pada asas kepentingan umum dalam masyarakat. 3) Pemimpin harus menampung aspirasi masyarakat, yang mengacu pada asas untuk menyelesaikan masalah dalam masyarkat. Sementara itu, matriks dalam teks novel tersebut adalah "Konsep Pemimpin Ideal" yang mengarah pada model mengayomi dan merangkul masyarakat sebagai rakyat yang dipimpin. Variannya adalah teks-teks yang berkaitan dengan kepemimpinan ideal yang ada dalam teks novel. Hipogram potensial sama seperti matriks yaitu konsep pemimpin ideal, sedangkan hipogram aktualnya adalah kisah dibalik munculnya novel yang mencakup masa kecil Najib Kailani yang tumbuh dan berkembang $d$ itengah penjajahan Inggris, kemudian pada tahun 1958-1965 ia pernah merasakan keluar masuk penjara karena tergabung dalam kelompok oposisi pemerintah AlIkhwan, dan pada tahun 1981 novel $A n$ Nidaul Khalidmuncul sebagai karya sastra yang ditulis oleh Najib Kailani.

\section{Daftar Pustaka}

Afriansyah, Ade. 2017. Konsep Pemimpin Ideal Menurut Al-Ghazali. Jurnal Nalar Vol 1, No 2.

Ahmad, Zainal Abidin. 1975. Konsepsi Negara Bermoral Menurut Imam Al-Ghazali. Jakarta: Bulan Bintang

Ahyar, Juni. 2019. Apa Itu Sastra: JenisJenis Karya Sastra Dan Bagaimanakah Cara Menulis Dan Mengapresiasi Karya Sastra. Yogyakarta: Deepublish

Al-Ghazali. Ihya' 'Ulumuddin, Cet II. Beirut: Dar Kutub Al-Ilmiyah.

Al Kailani, Najib. 2000. Panggilan Abadi. Yogyakarta: PT. Prasetia Widia Pratama

Azzuhri, Muhandis. 2008. Nasionalisme Religius dalam Novel Al-YaumulMau'uddanAn-Nida@ul Kha@lid Karya Najib Kilani: Analisis Intertekstual. Yogyakarta: Universitas Gadjah Mada

Endraswara, Suwardi. 2003. Metode Penelitian Sasstra. Yogyakarta: Penerbit Pustaka Widyatama.

Hakim, Abdul. 2007. Kepemimpinan Islami. Semarang: Unissula Press.

Hikmat, Mahi M. 2011. Metode Penelitian: dalam Perspektif Ilmu Komunikasi dan Sastra. Yogyakrta: Graha Ilmu.

Imron, Dkk. 2017. Kajian Semiotika Dalam Nove Gajah Mada: Sanga Turangga Paskowani Karya Langit Kresna Hariadi. Lingua Franca. Vol. II. 
Kailani, Najib. 1981. An-Nida@ul Kha@lid. Beirut: Muassasatu AlRisalah

Latifi, Yulia Nasrul. 2004. Nasionalisme dalam Novel An-Nida'U Al-Khalid Karya Najib Kaylani. Yogyakarta: Universitas Gadjah Mada

Nurgiyantoro, Burhan. 2009. Penilaian Dalam Pengajaran Bahasa dan Sastra. Yogykarta: BPFE

Pradopo, Rahmat Djoko. 1999. Semiotika: Teori, Metode, Dan Penerapannya Dalam Pemaknaan Sastra. Humaniora, Vol 11

Pradopo, Rachmat Djoko. 2002. Kritik Sastra Modern. Yogyakarta: Gama Media

Ratna, Nyoman Kutha. 2004. Teori, Metode, dan Teknik Penelitian Sastra. Yogyakarta: Pustaka Pelajar.

Siswanto, Wahyudi. 2008. Pengantar Teori Sastra. Jakarta: PT. Grasindo.

Sumardjo, Jakob dan Saini. 1997. Apresiasi Kesusastraan. Jakarta: Gramedia Pustaka Utama.

Syafethi. 2016. Semiotika Riffaterre: Kasih Sayang Pada Puisi "An Die Freude" Karya Johann Christoph Friedrich Von Schiller. Yogyakarta: Skripsi Universitas Negeri Yogyakarta

Utami, Ajeng Wahyu. 2018. Al- Riwayah "Al Nida' Al Khalid" Linajib Al Kaylaniy: Dirasah Tahliliyah Ijtimaiyah Adabiyah 'Alan Swingggewood. Yogyakarya: UIN Sunan Kalijaga.

Wellek, Rene dan Austin Warren. 1993. Teori Kesusastraan: Terj. Budiyanto. Jakarta: Gramedia Pustaka Utama. 